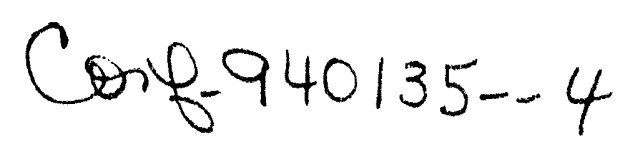

\title{
TENSILE STRENGTH OF DRIED GELCAST GREEN BODIES
}

Stephen D. Nunn, Ogbemi O. Omatete, Claudia A. Walls, and Dixie L. Barker

Oak Ridge National Laboratory, Oak Ridge, TN 37831-6087

Ceramic green bodies were prepared by three different techniques, dry pressing, slip casting, and gelcasting. The tensile strength of the green bodies was measured using a diametral compression test. It was found that the gelcast samples were from 2 to 20 times stronger than the conventionally formed green bodies. SEM examination of the gelcast samples revealed a homogeneous, brittle fracture surface indicating a very uniform distribution of the binder and excellent dispersion of the ceramic powder.

\section{INTRODUCTION}

Gelcasting is a ceramic forming process which offers distinct advantages as an alternative to the more conventional ceramic forming methods such as dry pressing, slip casting, and injection molding. ${ }^{1-4}$ Principal advantages include near-net-shape forming, high green density, and low organic levels in the dried green ceramics. A wide variety of ceramic materials have been prepared using the gelcasting process. These include silicon nitride, silicon carbide, alumina, and zirconia, among others. Significant improvements have been made in the gel-forming chemical solution to lower the toxicity of the monomer components and to shift to a water-based system.

During the development of the gelcasting process for forming ceramic materials, it was observed that the ceramic green bodies had unusual characteristics compared to conventionally processed materials. ${ }^{5}$ In particular, it was noted that the gelcast materials seemed to be exceptionally strong. However, this was only a qualitative assessment. In preparing ceramic green bodies, strength is an important parameter and can limit the size and shape of the components which can be safely formed and handled. High strength would be a significant advantage for production of large structures. The present study was undertaken to quantitatively determine the strength of gelcast ceramic green bodies and to compare the strength of the gelcast materials to conventionally formed materials.

\section{EXPERIMENTAL PROCEDURE}

Slurry batches for dry pressing and slip casting were prepared by wet ball milling alumina powder (Reynolds RC-HP DBM) and the binder in a polyurethane-lined mill containing $6 \mathrm{~mm}$ cylindrical alumina media. The batch size was approximately
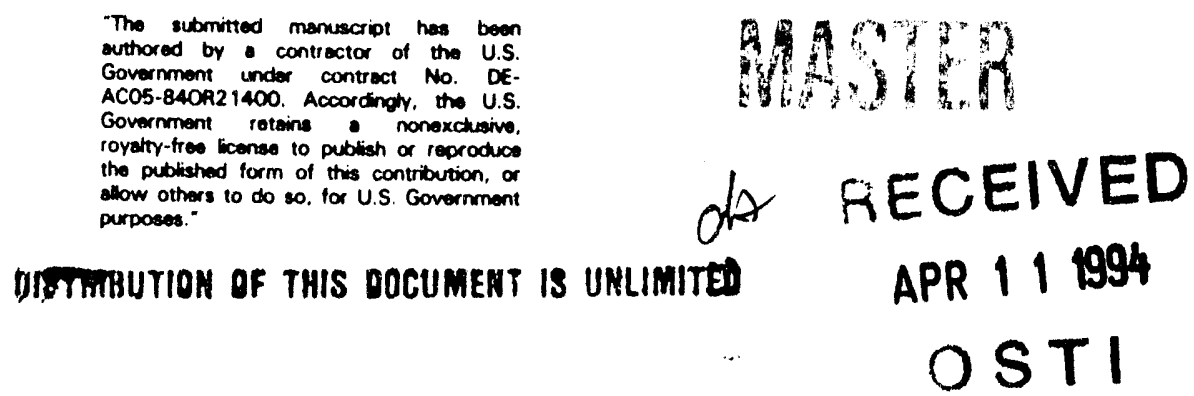
Table I. Green body strength measured by diametral compression testing.

\begin{tabular}{|c|c|c|c|c|c|c|}
\hline \multirow[b]{2}{*}{ Material* } & \multirow{2}{*}{$\begin{array}{c}\text { Green Body } \\
\text { Type }\end{array}$} & \multirow{2}{*}{$\begin{array}{l}\text { Binder } \\
(w t . \%)\end{array}$} & \multirow{2}{*}{$\begin{array}{l}\text { Number } \\
\text { of Tests }\end{array}$} & \multicolumn{2}{|c|}{ Green Density } & \multirow{2}{*}{$\begin{array}{l}\text { Tensile Strength } \\
(\mathrm{MPa})\end{array}$} \\
\hline & & & & $(\mathrm{g} / \mathrm{cc})$ & \% Th.D & \\
\hline Alumina & Dry Pressed & $3.07 \%$ PVA & 21 & 2.13 & 53.5 & $0.16 \pm 0.03$ \\
\hline Alumina & Dry Pressed & $\begin{array}{l}3.75 \% \text { PVA + } \\
1.25 \% \text { Carbowax }\end{array}$ & 12 & 2.38 & 59.8 & $0.60 \pm 0.20$ \\
\hline Alumina & Slip Cast & $\begin{array}{l}3.75 \% \text { PVA + } \\
1.25 \% \text { Carbowax }\end{array}$ & 6 & 2.11 & 53.0 & $1.88 \pm 0.04$ \\
\hline Alumina & Gelcast & $3 \%$ MAM/MBAM & 8 & 2.33 & 58.5 & $2.93 \pm 0.85$ \\
\hline Silcon Nitride & Gelcast & $5 \%$ MAM/MBAM & 7 & 1.68 & 52.1 & $3.24 \pm 0.29$ \\
\hline
\end{tabular}

- Alumina: RC-HP DBM. Malakoff Industries, Malkoff, TX

Silicon Nitride: SN E-10, UBE Induseries, New York, NY

$2 \mathrm{~kg}$ of alumina powder. The binder content was varied as indicated in Table I. One of the dry pressed batches contained $3.07 \mathrm{wt} . \%$ polyvinyl alcohol (PVA, DuPont Elvanol 75-15), while the second dry pressed batch and the slip cast batch contained 3.75 wt.\% PVA plus 1.25 wt.\% Carbowax (Union Carbide, Carbowax PEG 8000).

The dry pressed powder was obtained by drying the ball milled slurry in an oven at $50^{\circ} \mathrm{C}$, crushing the dried powder using a mortar and pestle, and then sieving the powder through a 200 mesh screen. Disks were formed by compacting approximately $60 \mathrm{~g}$ of powder in a $57 \mathrm{~mm}(2.25 \mathrm{in}$.) diameter cylindrical die at 13.8 $\mathrm{MPa}(2 \mathrm{ksi})$ using a uniaxial press, followed by isostatic pressing at $344.8 \mathrm{MPa}$ (50 ksi).

The slip casting slurry was vacuum deaired and cast in $57 \mathrm{~mm}$ diameter cavities in plaster of paris molds. After the casting was complete, the sprues were removed and the disks were dried in an oven at $40^{\circ} \mathrm{C}$.

Gelcasting slurries of alumina and silicon nitride (UBE E-10) were prepared by turbomilling the ceramic powders in an aqueous suspension. The alumina slurry contained 52 vol.\% ceramic, while the silicon nitride slurry contained 46 vol. $\%$ powder. The amount of organic binder in the slurries was $15 \mathrm{wt} . \%$ of the liquid. Because the alumina slurry had a higher solids loading and the density of alumina is higher than that of silicon nitride, the amount of binder in the gelcast alumina samples was about $3 \mathrm{wt}$.\% while that in the gelcast silicon nitride was about $5 \mathrm{wt} . \%$ as shown in Table I. After milling, the slurries were vacuum deaired and cast in 57 mm diameter anodized aluminum molds. The cast samples were placed in an oven at $60^{\circ} \mathrm{C}$ for $30 \mathrm{~min}$. to gel. After cooling, the samples were removed from the molds and placed in a controlled temperature and humidity chamber for the initial drying step. The chamber was maintained at $25^{\circ} \mathrm{C}$ and $92 \%$ relative humidity. The samples were kept in the chamber for approximately 16 hours until shrinkage was 
complete. The samples were then removed from the chamber and placed in a cabinet under ambient conditions to complete the drying process.

In preparation for the diametral compression test, the disks were trued to assure that the faces were flat and parallel, and that the edges were flat and perpendicular to the faces. The finished disks were typically $55 \mathrm{~mm}$ in diameter and from 8 to $12 \mathrm{~mm}$ in thickness. The diametral compression tests were conducted by placing the diskshaped specimens on edge between two flat platens on a universal testing machine and applying a compressive load. A tensile stress is generated perpendicular to the compressive loading plane. The peak load was recorded on an $x-y$ plotter. The tensile stress, $\sigma$, was then calculated using the following equation:6-8

$$
\sigma=\frac{2 P}{\pi D t}
$$

where $P$ is the applied load, $D$ is the diameter of the disk, and $t$ is the thickness of the disk.

The fracture surfaces of the disks were examined by optical and scanning electron microscopy.

\section{RESULTS AND DISCUSSION}

The diametral compression test $6-8$ is a convenient and simple method for obtaining a measure of the tensile strength of brittle materials. Some care must be taken in sample preparation and sample size may have an effect on test results. ${ }^{8}$ In addition, only materials which have isotropic properties and which are significantly stronger in compression than in tension will yield valid results. 9 However, many ceramic materials satisfy these requirements and the test can be useful for comparison of properties. Typical fracture patterns observed during the diametral compression testing are shown in Fig. 1. These patterns are indicative of true tensile failures. Shear induced failure would result in more diagonal fracture lines and greater fragmentation of the test sample. Compressive failure would be accompanied by severe crushing damage at the loading points. These observations indicate that the test was valid for determining the tensile strength of the green bodies.

A summary of the test results is given Table I. Although the packing density of the green bodies varied from about 52 to $60 \%$, there does not appear to be a direct correlation between the observed green density and the measured tensile strength. There is, however, a clear relationship between the forming method and the strength. The dry pressed samples had the lowest strengths, $0.16 \mathrm{MPa}(23 \mathrm{psi})$ for the samples with PVA binder only and $0.60 \mathrm{MPa}$ (87 psi) for the samples containing PVA and Carbowax. The slip cast samples were considerably stronger, $1.88 \mathrm{MPa}(273 \mathrm{psi})$. And the gelcast samples showed the highest strengths, 2.93 $\mathrm{MPa}$ (425 psi) for the alumina containing $3 \mathrm{wt} . \%$ binder and $3.24 \mathrm{MPa}$ (470 psi) for the silicon nitride material containing 5 wt.\% binder. A comparison of the tensile strengths is shown graphically in Fig. 2. 


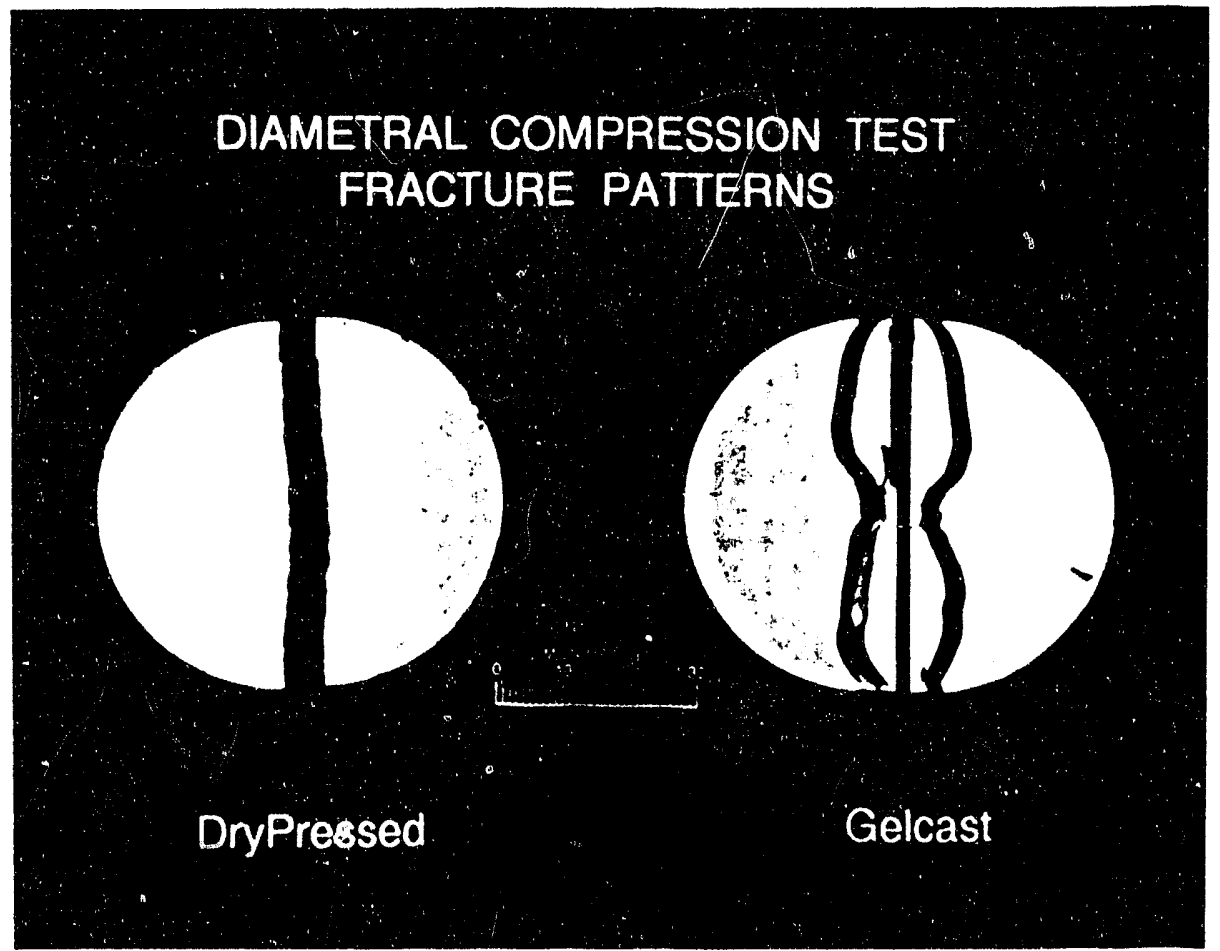

Figure 1. Disk shaped ceramic green bodies fractured in the diametral compression test. The principal fracture was along the loading line, indicating tensile failure. The disks are $55 \mathrm{~mm}$ in diameter.

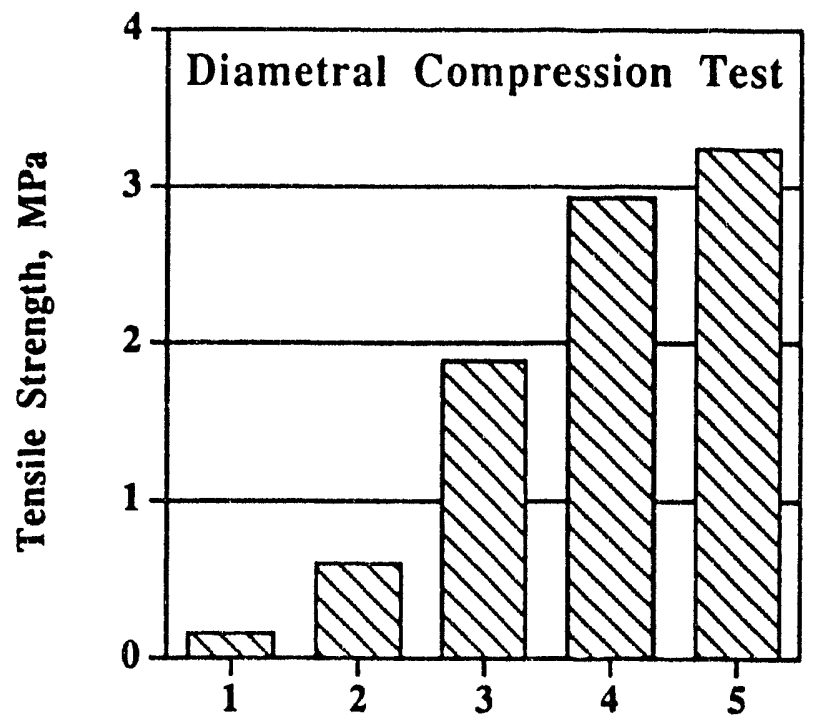

1. Alumina, Dry Pressed 3.07 wt.\% PVA

2. Alumina, Dry Pressed 3.75 wt.\% PVA + 1.25 wt.\% Carbowax

3. Alumina, Slip Cast 3.75 wt. \% PVA + 1.25 wt.\% Carbowax

4. Alumina, Gelcast 3 wt.\% MAM/MBAM

5. Silicon Nitride, Gelcast 5 wt.\% MAM/MBAM

Figure 2. Comparison of the tensile strength of ceramic green bodies measured by diametral compression testing. 

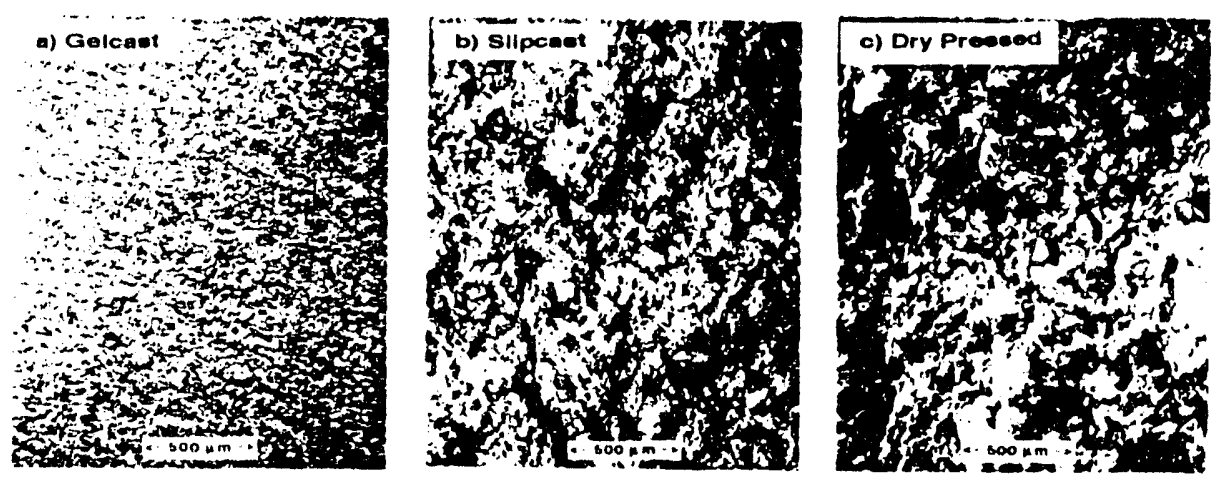

Figure 3. Scanning electron micrographs of the fracture surfaces of alumina samples after diametral compression testing.

The fracture mode as illustrated in Fig. 1 was related to the measured strengths. Weaker samples showed a simple single fracture along the loading line, while the stronger samples exhibited multiple, parallel fractures. This behavior is similar to the results reported by Ovri and Davies for sintered silicon nitride. 8 The dry pressed and slip cast samples all failed in the single fracture mode, while nearly all of the gelcast samples showed the multiple fracture pattern.

The microstructure of the fracture surfaces of the test samples was examined using optical microscopy and scanning electron microscopy (SEM). Examples of the microstructures observed for the alumina samples formed by the three different methods are shown in Fig. 3. These examples are typical of the fracture surfaces associated with the different forming processes. There is a clear distinction between the roughness of the surfaces of the dry pressed and slip cast samples compared to the gelcast material.

The high degree of roughness of the dry pressed and the slip cast samples indicates a non-uniform distribution of the binder and considerable particle agglomeration. There also appears to be larger pores in the microstructure of these samples. In contrast, the gelcast sample shows a very uniform fracture surface indicating a homogeneous distribution of the binder in the microstructure. The gelation reaction forms a highly crosslinked acrylic polymer. When dried, this polymer is very strong, hard, and brittle. The uniform distribution of this binder in the gelcast materials combined with the absence of large flaws due to particle agglomeration or porosity appears to be the reason for the exceptionally high strength of these samples. 


\section{CONCLUSIONS}

Diametral compression testing was used to determine the tensile strength of ceramic green bodies formed by dry pressing, slip casting, and gelcasting. It was found that the gelcast samples were 5 to 20 times stronger than the dry pressed samples and about twice as strong as the slip cast material. There was no apparent correlation between the green density and the strength. The higher strength of the gelcast materials was attributed to the homogeneous distribution of the binder and to the inherent high strength of the acrylic polymer which is formed in the gelling process.

\section{ACKNOWLEDGMENTS}

Research sponsored by the Ceramic Technology Project, DOE Office of Transportation Technologies, under contract DE-AC05-84OR21400 with Martin Marietta Energy Systems, Inc.

\section{REFERENCES}

1. M. A. Janney and O. O. Omatete, "Method for Molding Ceramic Powders Using a Water-Based Gelcasting," U. S. Pat. No. 5028 362, July 2, 1991.

2. A. C. Young, O. O. Omatete, M. A. Janney, and P. A. Menchhofer, "Gelcasting of Alumina," J. Am. Ceram. Soc., 74 [3] 612-18 (1991).

3. O. O. Omatete, M. A. Janney, and R. A. Strehlow, "Gelcasting-A New Ceramic Forming Process," Am. Ceram. Soc. Bull., 70 [10] 1641-49 (1991).

4. M. A. Janney and O. O. Omatete, "Method for Molding Ceramic Powders Using a Water-Based Gelcasting Process," U. S. Pat. No. 5145 908, Sep. 8, 1992.

5. S. D. Nunn, O. O. Omatete, C. A. Walls, and K. L. Ploetz, "Improved Processing and Properties of Gelcast Ceramics," Paper No. SXIII-96-93, presented at the 95th Annual Meeting of the American Ceramic Society, Cincinnati, OH, April 19-22, 1993.

6. F. L. L. B. Carneiro and A. Barcellos, "Concrete Tensile Strength," Union of Testing and Research Laboratories for Materials and Structures, 13 March, 1953, p. 98.

7. T. Akazawa, "Tension Test Method for Concrete," International Association of Testing and Research Laboratories for Materials and Structures, 16 November, 1953, p. 11.

8. J. E. O. Ovri and T. J. Davies, "Diametral Compression of Silicon Nitride," Mater. Sci. and Eng., 96 109-116 (1987).

9. A. Okada, "Diametral Compression Tests of Silicon Carbide Fibre-Reinforced Glass," J. Mater. Sci., 25 3901-05 (1990).

\section{DISCLAIMER}

This report was prepared as an account of work sponsored by an agency of the United States Government. Neither the United States Government nor any agency thereof, nor any of their employees, makes any warranty, express or implied, or assumes any legal liability or responsibility for the accuracy, completeness, or usefulness of any information, apparatus, product, or process disclosed, or represents that its use would not infringe privately owned rights. Reference herein to any specific commercial product, process, or service by trade name, trademark, manufacturer, or otherwise does not necessarily constitute or imply its endorsement, recommendation, or favoring by the United States Government or any agency thereof. The views and opinions of authors expressed herein do not necessarily state or reflect those of the United States Government or any agency thereof. 

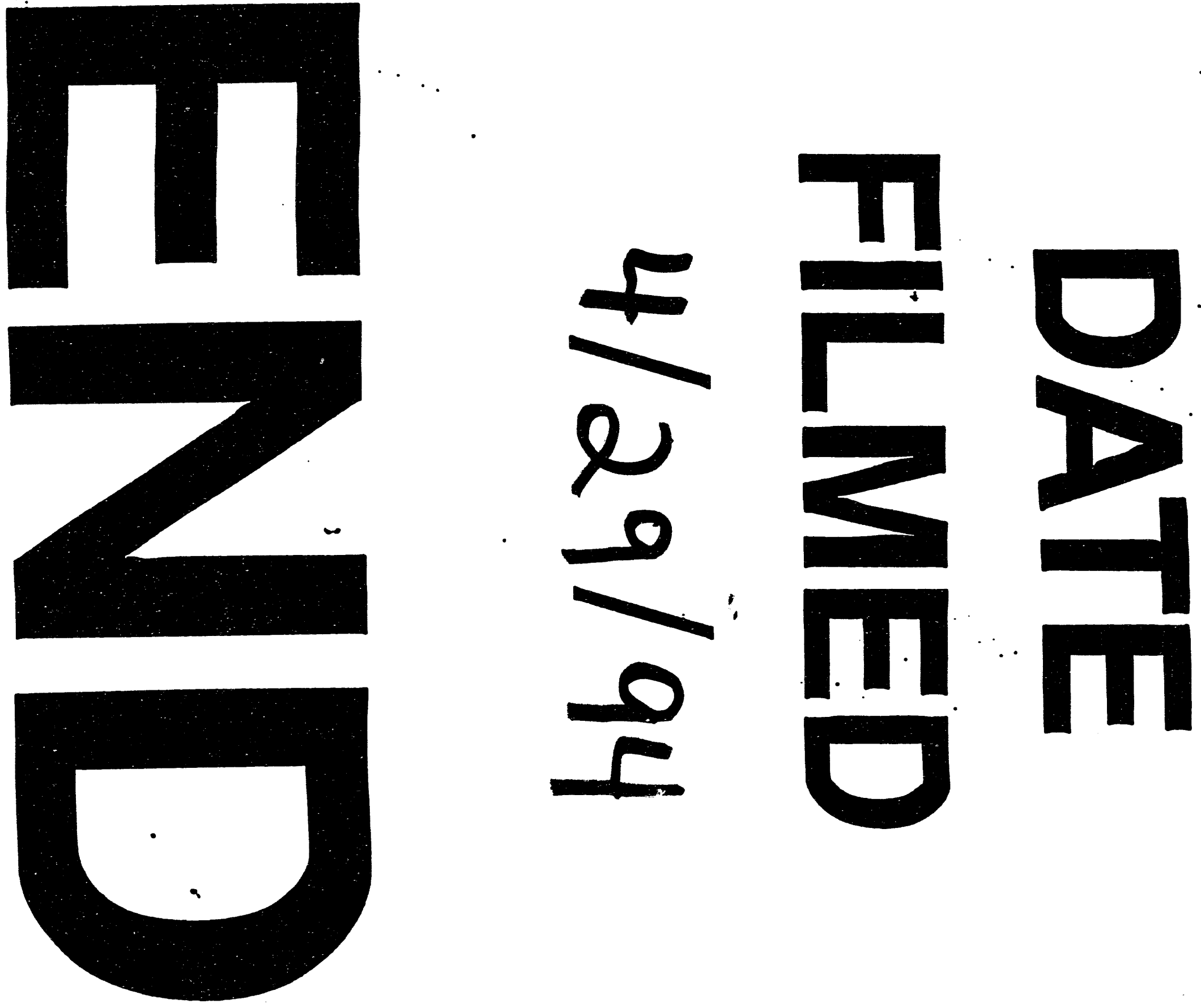
